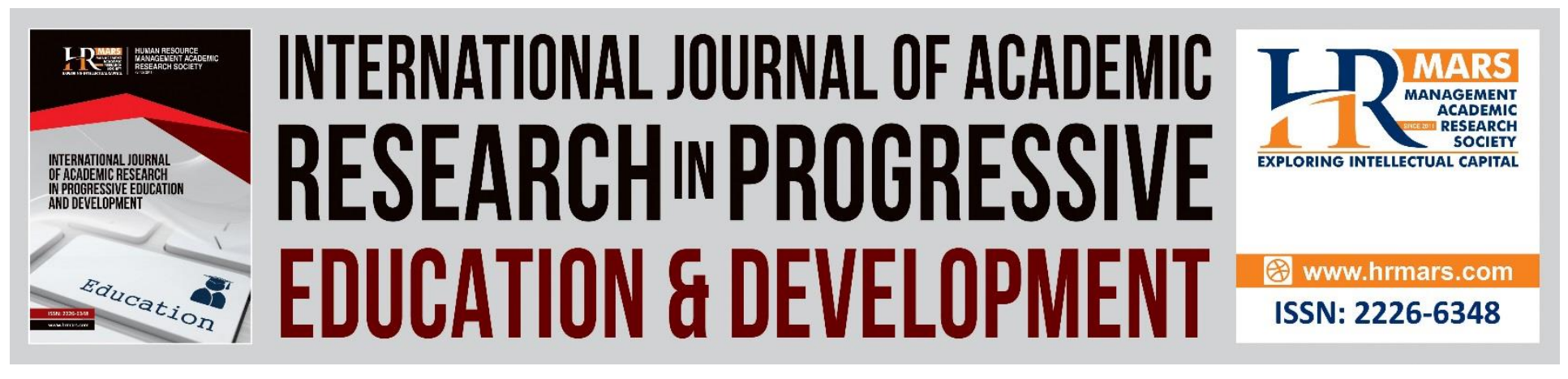

\title{
Information Industry: Characteristics and Mechanism for the Development
}

Saiful Farik Mat Yatin, Zulkifli Mohammed, Ahmad Affendi Mohd Nasir, Mohd Mustafa Kamal Abdul Wahid, Charles A/K Kiroh

To Link this Article: http://dx.doi.org/10.6007/IJARPED/v7-i3/4359

DOI: $10.6007 /$ IJARPED/v7-i3/4359

Received: 15 June 2018, Revised: 29 June 2018, Accepted: 13 July 2018

Published Online: 23 July 2018

In-Text Citation: (Yatin, Mohammed, Nasir, Wahid, \& Kiroh, 2018)

To Cite this Article: Yatin, S. F. M., Mohammed, Z., Nasir, A. A. M., Wahid, M. M. K. A., \& Kiroh, C. A. (2018). Information Industry: Characteristics and Mechanism for the Development. International Journal of Academic Research in Progressive Education and Development, 7(3), 200-210.

Copyright: () 2018 The Author(s)

Published by Human Resource Management Academic Research Society (www.hrmars.com)

This article is published under the Creative Commons Attribution (CC BY 4.0) license. Anyone may reproduce, distribute, translate and create derivative works of this article (for both commercial and non-commercial purposes), subject to full attribution to the original publication and authors. The full terms of this license may be seen

at: http://creativecommons.org/licences/by/4.0/legalcode

Vol. 7, No. 3, July 2018, Pg. 200 - 210

http://hrmars.com/index.php/pages/detail/IJARPED

JOURNAL HOMEPAGE

Full Terms \& Conditions of access and use can be found at http://hrmars.com/index.php/pages/detail/publication-ethics 


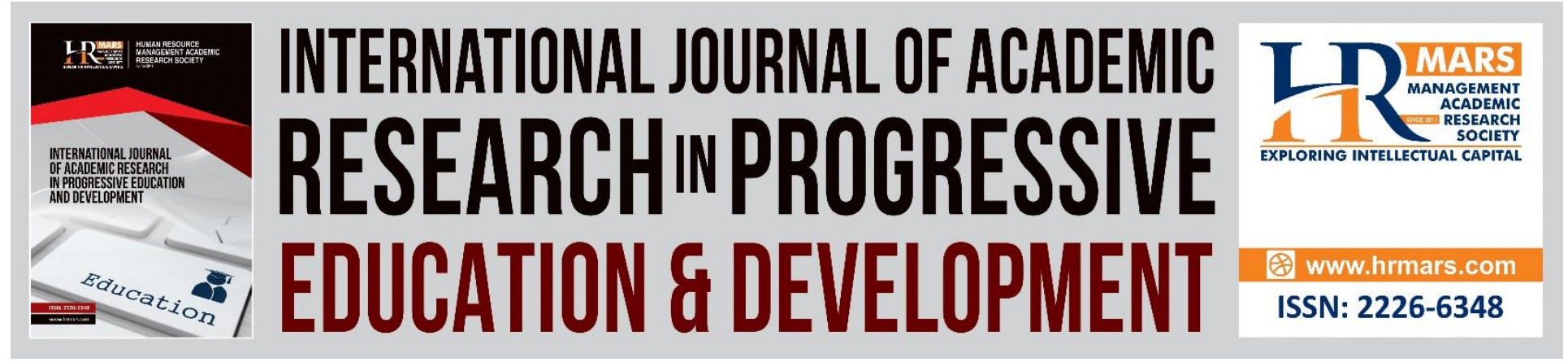

\title{
Information Industry: Characteristics and Mechanism for the Development
}

\author{
Saiful Farik Mat Yatin, Zulkifli Mohammed, Ahmad Affendi Mohd \\ Nasir, Mohd Mustafa Kamal Abdul Wahid, Charles A/K Kiroh \\ Faculty of Information Management, Puncak Perdana Campus, Universiti Teknologi MARA, \\ UiTM Selangor, Malaysia \\ Email:farik@salam.uitm.edu.my, zulmohammed@gmail.com
}

\begin{abstract}
The purpose of this paper is to study the characteristics and the pattern and mechanisms for its development and investigate the exact definition and scope of information industry to measure the industry's contribution towards the growth of country's economy. Each definition of information industry provides different result towards the growth of gross domestic product (GDP) for the industry. The importance of true definition of information industry is significant for the industry's contribution towards the growth of national economic. It is necessary to find the mechanism to enhance and boost the development of this industry. The pattern of this industry development was found to have a significant effect on the growth of this industry. This paper discussion was based on several articles regarding the information industry which is still brandnew industry in the country. The lack of research about the industry limits the findings of the information industry. The significance of study the mechanism and pattern of this industry could aid the boost and development of this information industry.

Keywords: Information Industry, Mechanism, Pattern, Characteristics, Information Management

\section{Introduction}

Without a doubt, information has become an integral part of our daily tasks. The emergence of the importance of information began in the early days of the mankind when people started using information for decision making and problem solving. As the new-in thing, the information industry is the mixture of fast-growing software, hardware, services, the enterprises, moderategrowth traditional content publisher and media.

Information can be regarded as the raw data that has been processed for the benefit of the recipient, to meet the objective. Information is highly regarded as the valuable assets for the living organism. Information is the power. The definition of information depends on the context in which the information originated and the context in which it is interpreted. It is agreeable that the meaning of information is well-known to all the society. The lay person, asked to define
\end{abstract}


Vol. 7, No. 3, July 2018, E-ISSN: 2226-6348 ๑ 2018 HRMARS

information, is most likely to regard it as an item of information or intelligence, a fact or circumstance of which one is told (Madden, 2000). According to Merriam-Webster Dictionary, information can be defined as knowledge obtained from investigation, study, or instruction, or intelligence and news or facts and data. However, there is lack of research has been conducted to determine the definition and scope of information industry. Most researches only estimate the GDP of information industry without having explained what can be illustrated as the information industry.

\section{What is Information Industry?}

There is no single definition of "What is Information Industry" as the concepts keep changing and evolving with time. Few studies focus on Information industry without explaining the concept and scope of information industry. The information industry should be defined properly for the measurement of contribution towards national economic. What is belongs to information industry should be explained accordingly.

This paper makes three (3) key discussions. First, to investigate the characteristics of the information industry, to study the mechanism of development and to observe the pattern that being applied for the growth and enhancement of this industry. Based on the characteristics, mechanisms and the patterns, this paper is able to demonstrate the clear definition what is information industry all about. Finally, the paper conclusions and recommendations for development of this industry and further research.

\section{Characteristic of Information Industry}

Chen (2016) said that in his journal Characteristics and Development of Information Industry and Its Impact on the Economy in other country information industry is known as $3 \mathrm{C}$, where its combine of communication, computer and content. From this perspective, this not only includes the manufacturing of information equipment and the communication, it also includes the even larger information-service industry with information resource development and utilization as its content.

The main method to measure the existing information industry and its application analysis is:

1. Shan Chan in his journal mentions that, there is several differences scope of the information industry. Researchers combining all the definitions for the information industry to make sure outcome of the definitions is suite with environment. Today's information industry gradually grown their scope. No longer use the old standard definitions. Original measurement system indicators may also no longer apply; thus, they must be readjusted.

2. The various scopes of information industries are also play an important role in this new era of information. The grown of information industry shows a trend to close to the individual whereas the used of application, email and others shows the improvement of living quality also reflected in the measurement system.

3. Information industries also promoting from traditional industry to modern industry. It's also promoting innovation integration to human living way.

Chen also mentions that, there is several differences scope of the information industry. Researchers combining all the definitions for the information industry to make sure outcome of 
Vol. 7, No. 3, July 2018, E-ISSN: 2226-6348 @ 2018 HRMARS

the definitions is suite with environment. Today's information industry gradually grown their scope. No longer use the old standard definitions. Original measurement system indicators may also no longer apply; thus, they must be readjusted. The various scopes of information industries are also play an important role in this new era of information. The grown of information industry shows a trend to close to the individual whereas the used of application, email and others shows the improvement of living quality also reflected in the measurement system. Information industries also promoting from traditional industry to modern industry. It's also promoting innovation integration to human living.

All ICT equipment is relocated to the hardware side of the information industry, while printed material, publishing of news, book, software development is belong to the software, also side of the information industry. The information industry is equal as the human being whereas the hardware is the support of the bones and the software is the nerves that make the human being completed.

Information industry has the similarity to the development of science and technology and it can be split into three distinctive stages, that is:

1. Electronic media is one of the big step into information industry. At this stage, the information transfer is transmitted directly to others.

2. The development of internet is increasingly the development of information industry and attained the first apex. The use of media social, web browser can be thought as the information acquisition stage. The information content become more and more complex.

3. New development of information industry is to cater the new focus that is big data mining, cloud storage, e-commerce. Information that based on ICT nowadays not only as the information disseminator, but today the function of information is as brain in creating any decision.

According to the research made by Abdrakmanova and Kovaleva (2016), they have noted that the International Statistical Practice suggests using two (2) subject groups to describe the Information Industry i.e. the ICT sector and the Content and media sector as the Information Industry generally refers to the wide-ranging manufacture and provision of goods and services linked to ICT and directly to the information.

\section{Mechanism for the Development of Information Industry}

There are various factors that contribute towards the development of this information industry.

\section{Development and Applications}

Main factor is the development and applications of various information technologies. The fusion of hardware, internet, software, tech companies and media expedite the development of this information industry. As the world entering the Industrial Revolution 4.0, the digitalization era has entered the third wave of computing which it can be forecast that all the daily tasks can be controlled by just one single click.

\section{Demand and Supply}

Another factor for the growth of this industry is the domestic consumption demand, domestic investment demand and the export. Basically, demand and supply. Supply and demand are both key to the economic development and growth. Supply and demand have an important 
INTERNATIONAL JOURNAL OF ACADEMIC RESEARCH IN PROGRESSIVE EDUCATION AND DEVELOPMENT

Vol. 7, No. 3, July 2018, E-ISSN: 2226-6348 @ 2018 HRMARS

relationship that determines the prices of most goods and services and for the benefit of this information industry.

\section{Market Competition}

The next factor that influences the growth of industry is market competition in the industry. The rivalry among competitors trying to achieve such goals as increasing profits, market share, and sales volume by varying the elements of the marketing mix: price, product, distribution, and promotion enhance the development of the information industry.

Based on the factors above, it can be classified into several mechanisms for the development of information industry.

- Technology Innovation Promotion mechanism

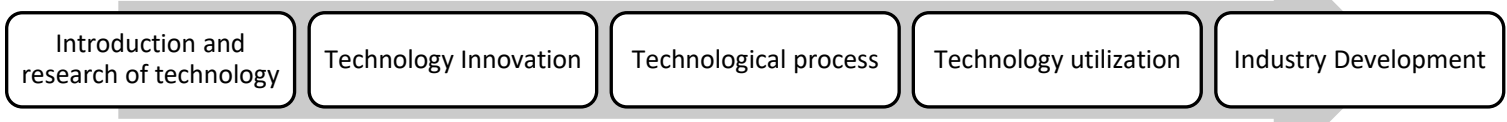

Figure 1: Technology innovation promotion mechanism

The discovery and innovation will link with information industry development. The innovation in this circumstance can be referred to the new products and new technologies. Industries with advanced technology will absorb a great deal of technical innovation achievements to promote production efficiency and to promote the production of elements and resources. Technology innovation will enhance the continuous growth of this industry. This technology innovation will aid the development of this industry, enhanced the depth and breadth of information's development and utilization, promoted the advancement of processing equipment and improve the information services way and expand its scope. The innovation of drone as per example, will aid the farmer in the paddy field to monitor their plantation at same time can increase production of the products and boost the national economy.

\section{- Market Demand Pulling Mechanism}

It is agreeable that demand is the key in development of economy and a main factor for the innovation of new products. Market demand can reflect the development situation of this industry's innovative activities but also can reflect consumers' acceptance with this industry's technological innovation and products. Market demand's influence on this information industry mainly reflected by economies of scale. The factors in this mechanism which is the domestic consumption demand, domestic investment demand and exports play important roles in the development of information industry. The greater the demand from the society, the greater the supply for the industry.

- Market structure and Competition Optimization Mechanism 


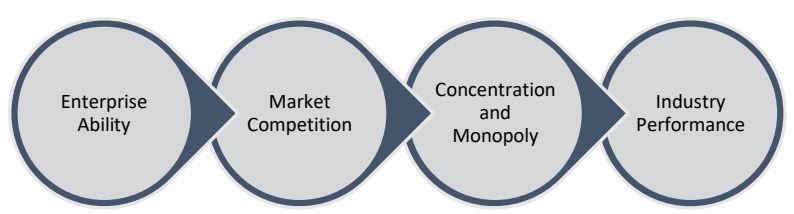

Figure 2: Market Structure and Competition Optimization

There is a causal relationship between market structure, market behavior and market performance. The hypothesis is market concentration extent decide the market behavior and the market behavior will affect the performance. The dynamic competition that available nowadays requires enterprises to create and innovate constantly and effectively and gaining a competitive advantage. Enterprise needs to focus on the available resources that meet the need of society. The enterprise can leverage the resources thus change the market structure and will boost the development of information industry.

- $\quad$ Policies, Regulations and the System Guarantee Mechanism

A policy is an intentional system of principles to guide decision making skill and fulfill rational outcomes. A policy is a statement of intent, and is implemented as a procedure or protocol. It is the rule that being formulated for constrain human's interaction behavior. Competition of the information industry shift from price-oriented to technological innovation oriented that the productivity of information industry growth rapidly and labor productivity way enhanced greatly (Renyong, Chaochao and Jingjing, 2012).

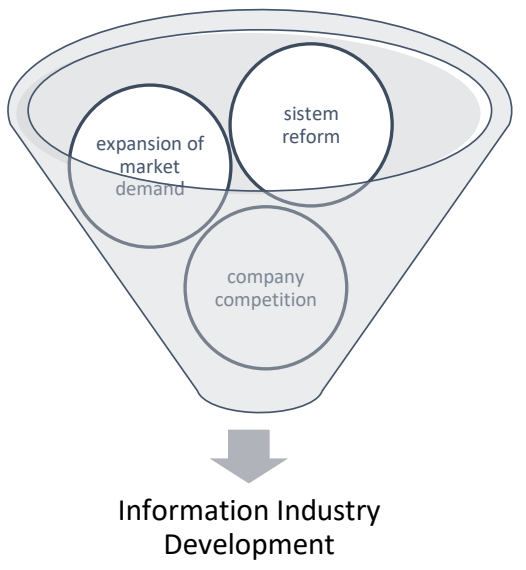

Figure 3: Policies, Regulations and the System Guarantee Mechanism

Policies and regulations of information industry and the system security mechanism can make the development of information industry policy to the scientific and reasonable direction, and promote the technological innovation of information industry and labor productivity rising to provide protection for nation information industry development. 
Vol. 7, No. 3, July 2018, E-ISSN: 2226-6348 @ 2018 HRMARS

\section{Pattern of Development of Information Industry}

Based on the factors that been used for mechanism for development of the information industry, the pattern of the development for the industry can be classified into many different approaches. It is best viewed according to the table below: -

\begin{tabular}{|c|c|c|}
\hline Approach & Development pattern & Countries \\
\hline \multirow[t]{2}{*}{ Industrial Structure } & Major breakthrough type & India and Ireland \\
\hline & Comprehensive pushed type & United States of America \\
\hline \multirow[t]{2}{*}{ Industrial organization } & Large enterprise dominated & USA, Japan and Korea \\
\hline & SMEs oriented mode & Taiwan \\
\hline \multirow[t]{2}{*}{ Industrial Layout } & OEM and ODM & Taiwan and India \\
\hline & OBM & USA and Japan \\
\hline \multirow[t]{2}{*}{ Technological Innovation } & Independent Innovation type & USA and Europe \\
\hline & $\begin{array}{l}\text { Introduction, digestion and } \\
\text { absorption type }\end{array}$ & Japan and Korea \\
\hline \multirow[t]{3}{*}{ Production Factors } & Technology driven & USA and Europe \\
\hline & Capital driven & Korea, Japan and Taiwan \\
\hline & Labor driven & China and Southeast Asia \\
\hline \multirow[t]{2}{*}{ International Trade } & Export oriented mode & Korea, Ireland and Taiwan \\
\hline & Domestic and foreign market & USA, Europe and Japan \\
\hline \multirow{2}{*}{$\begin{array}{l}\text { Subject of information } \\
\text { Development }\end{array}$} & Government leading & Indonesia \\
\hline & Enterprise dominated & USA \\
\hline \multirow[t]{2}{*}{ Funding source } & Foreign capital & India \\
\hline & Domestic capital & USA \\
\hline
\end{tabular}

Table 1: Classification of Development Pattern

For industrial structure, there are two development patterns. First, major breakthrough type where the country like India and Ireland innovate new technological products to drive the growth of the industry such as India developed the software industry. The comprehensive pushed pattern is by giving funds to development of the industry such as the United States of America. For industrial organization approach, it can be dividing into large enterprise against smallmedium enterprises. Since the large enterprise has enough resources to innovate new product, the industry innovation also started by the big enterprises. For small medium sized enterprises, the resources were scattered within different enterprises, thus the small medium size enterprise will initiate the development of information such as Taiwan.

For industrial layout approach, it can be categorized as Original Equipment manufacturing (OEM), Original Design Manufacturing (ODM) and Original Brand Manufacturing (OBM). Country like Taiwan and India use OEM and ODM pattern where the country use the trademark of the original unit and cooperation management mode in sales or business of original unit. USA and Japan use OBM mode where they operate their own brand to boost the development of the industry and enhance economic growth.

For technological innovation approach, it can be divided into independent innovation type and introduction, digestion and absorption type. For independent innovation type, country such as USA is doing independent research to innovate and for development of the industry to reach the demand. While for digestion and absorption type, the country like Japan and Korea will study 
Vol. 7, No. 3, July 2018, E-ISSN: 2226-6348 @ 2018 HRMARS

abroad about the key elements to innovate new product and imitate the same and practically applied to their information industry.

From the approach of production factors, country like USA and Europe use the technology driven mode where they relied on the research and development investment of technology to promote the development of information industry. Japan and Korea use the capital driven mode where they relied on the fund investments to drive the development of the industry. Country in South East Asia such as Malaysia used the labor driven mode to boost the production in information industry.

For International trade approach, the development pattern can be divided into export oriented method and where the domestic and foreign markets taking account. Korea and Japan use the former pattern by exporting to foreign market to meet the international demand and at the same time developed their information industry. For the latter mode is used to meet the international demand and domestic demand such the development mode in USA and Europe.

For the subject of information development, Indonesia is the example of country where the governments control the policies and regulations to meet the need of the people. For SMEs mode, the enterprise will do their research about new products to meet the demand in the market.

For the funding sources, it can be divided by foreign and domestic capital-dominated. The big countries such as USA used the latter capital-dominated to fund sources for development of information industry while India relied on foreign capital to drive the information industry.

\section{Discussion}

Based on the above study of characteristics, mechanisms and patterns of information developments, it is agreeable that the scope and context of information industry is bigger and wider. It is much depending on how the people define the word of information industry.

With the reference to the rigid definition of the information industry, which is begin in 1990 where as the rise of the structural changes in the economy lead to the what is called "postindustrial, the new economy, the k-economy, the e-economy, internet economy and the digital economy as a reflection to Information Industry era and there are many countries have been developing and adapting their national ICT strategies which resulting in the pursuit of new approaches to socio-economic development, to increase the competitiveness of the country. The comprehensive definition of the information industry will lead to the increment of the statistic of the information industry.

In order to identify development priorities and prospects in the information industry we need a clear understanding of what the information industry is, what its boundaries are, what forms of economic activity make up this economic segment and which products form in the corresponding market. Even the international classification and standards provide the general understanding of the information industry all about but additional research is needed to gain the clear picture of the Information Industry. The further research and study is necessary to ensure the correctness of the definition, involvement in due process of the information industry, the contribution of other towards the development of the information industries, the role paying by other enterprise in making the core information industry successful. 
Vol. 7, No. 3, July 2018, E-ISSN: 2226-6348 @ 2018 HRMARS

In the far greater detail of the new revision in 2007, the definition of the ICT sector which included; the enterprise whose operation give rise to goods intended to carry out the processing of information and services intended to carry out (or make it possible to carry out) the processing of the information. This kind of the definition has included any kind of the enterprise who involves in the information industry as the player of the segment. It does not matter how big the role is but it depends on the contribution to the production of the information product or any attempt to make the information product be realizes.

Thus, the Content and Media sector has included the Enterprise in this sector, who are engaged in the production, publishing and/or the distribution of content intended for people and the same criteria were used by the Central Product Classification (CPC). By the introduction of the comprehensive definition in information industries, it is impossible to establish internationally comparable the goods and services of the information industry.

Based on the article, it can be concluded that in Russian statistical practice, a definition of the information industry and its ICT sector was first introduced by the Federal State Statistics Service in 1998 where the Enterprise were identified as belonging to the ICT sector if at least 50 per cent or more of the goods and services produced during the financial year were ICT related and the result are considered to be goods and services intended primarily to carry out the processing of information. Meanwhile the Content and Media Sector is made up of enterprises engaged in economic activity linked to the production, publication, and/or distribution of content.

It can be summarized that, the grouping of the Information Industry in term of goods and services as the main analysis of the size and dynamics of the Information Industry make it possible to carry out comprehensive analysis, research and data complication for the benefit of the product markets and the potential of the domestic ICT manufacturing and the Information Industry reflected on the people need, particularly in archiving the state programmers under the Russian Information Society (2011-2020). Whereby the include of the goods and services predominantly intended to carry out and created the necessary conducive condition to carry out the processing of information or communications using particular electronic equipment, include the transfer, share, storage and visual presentation of data.

Upon the clear definition of the information industry which included the manufacture of office equipment, production of the insulated cable and wires, manufacturing the devices and any instruments to control, measure, test direct, navigate and for other purposes, the production of devices to regulated and control technological processes and the wholesale of the machinery, electronic equipment, hardware and the material of the same, lease of office machinery and computer equipment, and other relevant equipment the statistic of the industry has changes rapidly. The authors in the article has cited that on the basis of Rosstat data in 2014, considers that in Russian there is $3 \%$ ( 1.5 million persons) of the total state employment involving in the information industry, and 2,188 billion rubles value of the gross valued added of the Information Industry amounting to the $4 \%$ of the Russia's GDP meanwhile the growth was $54 \%$, i.e. $23 \%$ higher than the corresponding figure for GDP (31\%). 
Vol. 7, No. 3, July 2018, E-ISSN: 2226-6348 @ 2018 HRMARS

However, the best information industries for the labor market are Ireland, Switzerland Finland and Japan whereas the Russian Information Industry is comparable with Slovakia, France, Italy and Czech Republic. It is happened when they have included to the information industry segment of the enterprise which providing the services and goods with the information that could results to the increase of the economy activity linked to the publishing, production and the distribution of the media content where content is an organized message intended for the customer namely mere information documentary, entertainment products or the culture heritage matter.

We need the relevant data, accurate information and the correct approach to get the more precise estimates national's position in the Information Industry Society, meanwhile the single definition of the Information Industry will make assessment of the relevant activities, more transparent and ensure international compatibility of relevant statistics, which would allow estimating the country's role in the global development of the Information Industry.

\section{Conclusion}

This paper has concluded that the use of a single definition of the information industry makes it possible to carry out comprehensive analysis, foresight studies and international comparison based on the development figures for the information industry and digital economy and engages in full-scale monitoring of the development of the information society. There is an urgent need of the nation to have comprehensive methodological framework for setting the national information industry in near future. The new definition which included the ICT Sector and Content and Media Sector in the definition of the information industry will make assessment of the relevant economic activities more transparent and ensure international compatibility of relevant statistic, which would allow one or more precisely estimated our country position in the global economy. The authority must have the right and precise methodology framework, and for the academician, professional and the expert too, in further their research and study in the information industry. The kind of methodology will allow the expert to forecast the development of the national information industry, and to extend the said information industry methodology basic to set up the international ICT policy, in particular for setting the national information industry priorities.

\section{References}

Chen, S. (2016). Characteristics and Development of Information Industry and Its Impact on the Economy. Proceedings of $20152^{\text {nd }}$. International Conference on Industrial Economics System and Industrial Security Engineering, 9-18. https://doi.org/10.1007/978-981-287655-3

Abdrakhmanova, G., Kovaleva, G.G., \& Bulchenko, N.V. (2016). The information industry : Measuring Russia By International Standards. Higher School of Economics Research Paper No. WP BRP 56/STI/2016

Madden, A. D. (2000). A definition of information. Aslib Proceedings, 52(9), 343-349. https://doi.org/10.1108/EUM0000000007027 
INTERNATIONAL JOURNAL OF ACADEMIC RESEARCH IN PROGRESSIVE EDUCATION AND DEVELOPMENT

Vol. 7, No. 3, July 2018, E-ISSN: 2226-6348 (C) 2018 HRMARS

Renyong, H., Chaochao, F., \& Jingjing, W. (2012). A Study on the Engineering Dynamic Mechanism and Patterns of the Information Industry Development. Systems Engineering Procedia, 5(2009), 355-365.

https://doi.org/http://dx.doi.org/10.1016/j.sepro.2012.04.056 